\title{
O FENÔMENO RECRUTAMENTO E SELEÇÃO DE ENFERMEIROS EM HOSPITAIS: UM ENFOQUE FENOMENOLÓGICO*
}

\author{
Heloisa Helena Ciqueto Peres** \\ Paulina Kurcgant***
}

PERES, H.H.O,; KURCGANT, P. O fenômeno recrutamento e seleção de enfermeiros em hospitais: um enfoque fenomenológico. Rev.Esc.Enf.USP, v. 31, n.1, p. 129-49, abr. 1997.

Este estudo teve como objetivo, desvelar o processo de recrutamento e seleção de enfermeiros a partir da experiência dos sujeitos que vivenciam essa prática. Para tanto buscou-se como trajetória metodológica a fenomenologia, na modalidade do fenômeno situado no referencial de Joel Martins. Assim, o estudo foi realizado a partir do discurso de oito enfermeiros que experienciam o fenômeno. A análise dos depoimentos contemplou os momentos de descrição, redução e compreensão fenomenológicas, até o desvelamento da essencialidade do fenômeno investigado. Da análise fenomenológica dos discursos foi possivel resgatar aspectos que representam a compreensão geral do processo de recrutamento e seleção de enfermeiros. Dessa forma, a essencialidade do fenômeno desvelado caracterizou-se pelas relações Homem, Organizações e Sociedade, relações essas de interdependência permeadas por múltiplos determinantes transituacionais. Nessa perspectiva, novos horizontes abriram-se no que tange o pensar recrutamento e seleção em enfermagem.

UNITERMOS: Recrutamento e Seleção de Pessoal de Enfermagem. Recursos Humanos em Enfermagem. Administração de Pessoal de Enfermagem.

\section{INTRODUÇÃO}

\subsection{0 referencial teórico}

Para o delineamento do foco temático estudado faz-se necessário tecer considerações sobre o processo de recrutamento e seleção de pessoal, tendo como pano de fundo, a administração de recursos humanos na organização e na enfermagem.

* Este artigo é parte da Dissertação de Mestrado apresentada à Escola de Enfermagem da USP.

** Enfermeira. Professora Assistente do Departamento de Orientação Profissional da EEUSP.

*** Enfermeira. Professora Titular do Departamento de Orientação Profissional da EEUSP. Orientadora da Dissertaçăo de Mestrado. 
A administração de recursos humanos analisada historicamente passou, gradativamente, a ter marcante presença no mundo empresarial a partir da revolução industrial, principalmente, pelo crescente aumento da necessidade de pessoal nas empresas.

Entretranto, somente a partir do fim do século XIX e início do século XX é que a administração de pessoal adquiriu cunho científico com a explicitação dos pressupostos de Taylor e Fayol sobre a realidade do trabalho humano. $4,5,18,19,20$

Nesse contexto surge o desenvolvimento de processos científicos de seleção de trabalhadores visando a procura do homem adequado para o desempenho de atividades específicas, fundamentado no perfil físico dos operários e na concepção do homem como Ser econômico motivado, apenas, pela remuneração.

Posteriormente, outras teorias foram surgindo, encontrando respaldo nas ciências humanas e sociais, influenciando e explicando o gerenciamento de pessoal segundo diferentes estilos de administração de pessoal aliados a diferentes concepções de homem, surgindo a necessidade das organizações incorporarem uma visão mais humanista, fundamentada em princípios, valores, crenças e atitudes que implementassem e reconhecessem a contribuição dos empregados. Visão que possibilitasse uma abrangência, a partir da interpretação das influências do contexto externo e interno à organização, o que passou a constituir uma valiosa contribuição na elaboração das diretrizes de recursos humanos.

$\mathrm{Na}$ atualidade, os teóricos da administração são unânimes em conferir aos recursos humanos importância fundamental, sendo imprescindível a adoção de uma política, de valorização do ser humano, que promova espaço para que as pessoas possam expor seus pontos de vista, estimulando a criatividade, encorajando a libertação do pensamento e a individualização do homem para o sucesso das organizaçōes, onde as pessoas são o recurso central. O homem assim passa a ser concebido como um ser total, que exercita suas habilidades e capacidades de compreensão, comparação, escolha, decisão e participação.

Dessa forma, na visão atual, o recrutamento e a seleção são concebidos como um processo complexo, atrelado às propostas, políticas e objetivos organizacionais, ao mercado de trabalho, à situação social, política e econômica vigente e as necessidades individuais. $2,3,7,8,10,11,15,20$

Entretanto percebe-se que o elemento recursos humanos, ainda não é reconhecido em toda sua dimensão estratégica como uma fonte de resultados expressivos na cultura da administração brasileira. Sabe-se também que a descontinuidade das "políticas" econômicas brasileiras afetam a ação de recursos humanos, impedindo a plena execução dos seus programas. Nesse contexto ocorre a rotinização dos programas de pessoal sem a preocupação com o ser humano de forma holística. Nesse cenário o recrutamento e seleção torna-se um processo mecânico de contratar pessoal considerando apenas os aspectos quantitativos de pessoal.

Na realidade hospitalar, do ponto de vista da gestão de recursos humanos, observa-se que são poucos os hospitais que mantêm um política de 
desenvolvimento de pessoal desalienadora, voltada para a capacitação das potencialidades dos indivíduos, e que contemple de forma integrada a captação e a retenção de pessoal.

Nessa perpectiva, vários enfermeiros, ao analisarem o processo seletivo, revelam que este representa um grande desgaste aos individuos que trabalham nessa área, em decorrência da precária política de recursos humanos e das condições salariais inadequadas. ${ }^{14,16,17}$

Ao resgatar a historicidade da enfermagem, depreende-se que a participação do enfermeiro no processo seletivo em enfermagem procede desde a institucionalização da enfermagem, tendo à sua frente a pessoa de Florence Nightingale que adotava critérios caritativos e disciplinares, baseados na moral, obediência e confiança. ${ }^{1,6,9}$

Evidencia-se, ainda, que o processo seletivo estava presente nas escolas de enfermagem que admitiam duas categorias de enfermeirras: "Lady-Nurses", que possuíam uma alta posição social, e as "Nurses"que prestavam cuidado direto, sendo de nível socialmente inferior. Portanto, havia uma seleção, também, pautada em critérios sócio-econômicos.

$\mathrm{Na}$ atualidade a prática profissional do processo de recrutamento e seleção vem sendo realizada por enfermeiros, mecanicamente, de formsa reiterativa $e$ pouco reflexiva, fundamentada em modelos teóricos administrativos fincionalistaburocrático, das Teorias Clássicas e Burocráticas da Administração, privilegiando os aspectos técnico-normativos do processo, em um ideário caritativo e disciplinar.

Considerando que o processo de recrutamento e seleção de pessoal, principalmente na enfermagem, não pode ser desvinculado da dimensão existencial da vida humana pela especial peculiaridade que é a de estar orientado para selecionar pessoas que irão interagir e cuidar de outras, o processo seletivo em enfermagem deve resultar na valorização do ser humano e no autoconhecimento. Deve-se voltar para a compreensão da existência do homem, de suas necessidades, capacidades e desejos.

Dessa, forma, principalmente, por acreditar que o homem pode realizarse no trabalho e que o início desse processo ocorre no ingresso em uma instituição de trabalho esse estudo, na área de recursos humanos, teve como objetivo:

- Desvelar o processo de recrutamento e seleção de enfermeiros a partir da experiência dos sujeitos que vivenciam essa prática.

\section{A TRAJETÓRIA METODOLÓGICA}

\subsection{Considerações sobre a escolha do método}

A compreensão do processo seletivo, numa abordagem normativa e funcionalista desvinculada da dimensão existencial da vida humana, tem resultado em consequências negativas tanto para o individuo quanto para a 
organização. Dessa forma buscou-se compreender, no presente estudo, o processo seletivo a partir do cotidiano da prática da enfermagem.

Nessa perpectiva, evidenciou-se a necessidade de compreender o processo de recrutamento e seleção de enfermeiros por meio da percepção dos enfermeiros que vivenciam esse processo na enfermagem.

Assim, com esse propósito, considerou-se adequado o encaminhamento dessa pesquisa na vertente fenomenológica, na modalidade do fenômeno situado, fundamentado no referencial de MARTINS;BICUDO. ${ }^{12,13}$

Nessa concepção a fenomenologia como metodologia de pesquisa fica caracterizada pela descrição, redução e compreensão.

\subsection{A trajetória metodológica na pesquisa}

A região ontológica onde o fenômeno foi inquirido constituiu-se por enfermeiros que vivenciam o processo de recrutamento e seleção de outros enfermeiros em hospitais públicos e particulares do Município de São Paulo.

Assim, foi necessário clarificar, no contexto das instituições, os hospitais que contavam com enfermeiros que participavam e assumiam a responsabilidade pelo processo de recrutamento e seleção de outros enfermeiros. Esse critério foi adotado por considerar-se fundamental ouvir os enfermeiros que vivenciavam o processo para a definição do "locus" da pesquisa, ou seja, investigar o fenômeno seleção e recrutamento onde ele se mostrava "situado".

Para tanto, foram contactuados, por telefone, vinte e sete hospitais, dos quais dez não con tavam com a participação de enfermeiros no processo seletivo, sendo descartados.

Para a obtenção das descrições dos enfermeiros sobre o processo seletivo de enfermeiros utilizou-se a técnica da entrevista semi-estruturada, ficando as intervenções da pesquisadora limitadas à manutenção da entrevista segundo as seguintes questões norteadoras: "- Gostaria que você descrevesse o processo de recrutamento e seleção de enfermeiros vigente nessa Instituição; - Gostaria que você falasse sobre sua vivência como elemento participante desse processo de recrutamento e seleção."

A apreensão de dados biográficos dos entrevistados fez parte do primeiro momento da entrevista, objetivando o conhecimento de alguns aspectos do contexto e da história de vida dos sujeitos da pesquisa. Essa apreensão resgatou o "Tempo de formado e de serviço no hospital; tempo de participação no processo de recrutamento e seleção; capacitação profissional e específica para a realização do processo; cargo que ocupava e experiências profissionais anteriores".

A análise das descrições foi sendo processada concomitantemente à realização das entrevistas até o momento em que ocoresse o desvelamento da essencialidade do fenômeno investigado. Assim, foram obtidos dezessete discursos, dos quais oito constituíram a região de inquérito para a compreensão do fenômeno. 
Para a organização dos dados os discursos foram enumerados de I a VIII e integralmente transcritos, objetivando a captação de todo o conteúdo temático gerado.

Os momentos de análise seguiram as considerações de MARTINS ${ }^{12,13}$, compreendidas pela descrição, redução e compreensão.

A descrição fenomenológica é o primeiro passo da análise dos dados, onde ocorre o resgate de todas as informações obtidas, de forma precisa, segundo a forma pela qual o entrevistado apresentou-os em sua descrição, sem análises preliminares e prematuras.

Em seguida as descrições foram lidas, isoladamente e integralmente, na tentativa de obter-se ' a compreensão da linguagem dos enfermeiros, o sentido geral do todo' de cada depoimento e do conjunto dos depoimentos, sem interpretação ou identificação dos atributos nelas contidos, buscando-se a essencialidade do processo de recrutamento e seleção de enfermeiros.

Após sucessivas leituras das descrições, procedeu-se à redução fenomenológica, onde foram selecionadas as partes das descrições que foram consideradas essenciais para o desvelamento do fenômeno. Assim, destacou-se as unidades de significado que emergiram das descrições segundo um critério psicológico, a partir das mudanças de significado das situações descritas pelos enfermeiros, ou seja, da mudança de um valor para outro nas descrições.

Inicialmente essas unidades de significado foram tomadas exatamente como estavam propostas pelos sujeitos da pesquisa. Posteriormente as expressões cotidianas dos enfermeiros foram transformadas na linguagem da pesquisadora, que procurou reduzi-las em descrições essenciais para a compreensão do fenômeno.

Assim, analisou-se cada situação, atentamente, tentando reconhecer o seu sentido, descobrindo uma significação mais ampla e desprovida de ingenuidade, que contemplasse o implícito, as diferenças e as correlações existentes em cada discurso. Tentou-se penetrar no cotidiano onde o processo seletivo foi descrito, buscando-se a unidade e a consistência das diversas experiências relatadas.

O momento da análise ideográfica correspondeu à reflexão psicológica do individual. Tratou-se da análise da ideologia que permeia as descrições ingênuas do sujeito, fornecendo dados para a passagem do individual para o geral.

Nessa análise do individual foram expressas as percepções do pesquisador sobre as descrições dos sujeitos em uma linguagem própria, estando descritos, também, os dados biográficos de cada sujeito participante da pesquisa que auxiliaram na interpretação do fenômeno.

Seguindo-se a trajetória fenomenologica, o momento da compreensão, constituiu-se na análise nomotética, fundamentada na reflexão sobre os significados contemplados na descrição e na redução fenomenológica processados na análise ideográfica, envolvendo um conjunto de interpretações, na tentativa de desvelar a estrutura geral do fenômeno. 
$\mathrm{Na}$ análise nomotética buscou-se construir a estrutura geral do fenômeno a partir das convergências, divergências e idiossincrasias evidenciadas nas descrições.

O momento da compreensão constituiu-se das análises ideográfica e nomotética, onde buscou-se o desvelamento da estrutura geral do fenômeno recrutamento e seleção de enfermeiros, através das convergências, divergências e idiossincrasias contidas nos discursos.

\section{CONSTRUINDO OS RESULTADOS}

Inicialmente, procedeu-se à análise ideográfica, constituída da análise individual de cada discurso e posteriormente a análise nomotética, que possibilitou desvelar a estrutura geral do fenômeno "recrutamento e seleção de enfermeiros".

\subsection{Refletindo sobre a estrutura geral do fenômeno}

Considerando-se o momento da descrição e da redução fenomenológica, partiu-se para o momento da compreensão fenomenológica, que emerge da interpretação do pesquisador sobre as descrições.

Nesse momento da análise nomotética, buscou-se o desvelamento da estrutura geral do fenômeno recrutamento e seleção de enfermeiros, através das convergências, divergências e idiossincrasias contidas nos discursos.

Dessa forma foi possível resgatar, nos discursos dos enfermeiros, aspectos que representam a compreensão geral do processo de recrutamento e seleção de enfermeiros.

Subjacente às falas dos sujeitos da pesquisa depreendeu-se que o processo de recrutamento e seleção de enfermeiros é um fenômeno dinâmico de compatibilização das necessidades sociais, organizacionais e individuais, influenciado por múltiplos determinantes transituacionais decorrentes do contexto ambiental e organizacional. Como tal, não pode ser visualizado com a simplicidade de apenas preencher cargos de enfermeiros existentes nas instituições hospitalares voltado, exclusivamente, para a aplicação de procedimentos burocráticos e discriminatórios decorrentes do vínculo empregatício.

Nessa perspectiva, o processo de recrutamento e seleção é definido pela sociedade e sua concretização ocorre no âmbito organizacional através da relação interpessoal, candidato-profissional, visando a compatibilização das necessidades dos indivíduos, da organização e da sociedade.

Ficou evidente, também, no estudo, que a organização tem um papel predominante sobre as necessidades individuais e sociais. 
Essa tríade é permeada por múltiplos determinantes transituacionais decorrentes da situação social, política, econômica, cultural, educacional, trabalhista e de saúde vigentes no país; da cultura, dos pressupostos e objetivos organizacionais; das peculiaridades da enfermagem e das características pessoais e profissionais dos enfermeiros.

Evidenciou-se nos discursos dos enfermeiros que esses múltiplos determinantes influenciam o processo agindo como fatores facilitadores ou dificultadores, diversificando as formas de operacionalização do recrutamento e seleção de enfermeiros. A fala a seguir exemplifica isto:

II "(...) depende da época, depende de todo, de todo contexto interno e externo que a gente vive, desde o mercado de trabalho, política, recessão, como está a enfermagem... se tem muita gente saindo, evadindo, se tem muita gente querendo entrar... É claro que recrutamento de mão de obra tem muito a ver com a época sóciopolítica-econômica, recessão de mercado de trabalho, salário..."

Nos discursos II, V e VIII denotou-se que a clientela tem um papel determinante no perfil profissional dos enfermeiros, influenciando no qualitativo de recursos humanos. Desvelou-se que atualmente os clientes estão mais exigentes em relação à qualidade da assistência, sendo que a mídia e o código do consumidor colaboraram para essa conscientização, dos cidadãos em relação aos seus direitos à saúde. Esse processo de conscientização da população gera nos profissionais a necessidade de buscar o auto-desenvolvimento e a preocupação em desempenhar as atividades profissionais com maior responsabilidade.

Evidenciou-se, ainda, que os valores, crenças e preconceitos que permeiam a sociedade influenciam na determinação dos critérios seletivos para a escolha dos enfermeiros. Assim, o fato dos clientes apresentarem resistência em ser cuidados por homossexuais, depois do advento da AIDS, interfere na admissão de candidatos que apresentam essas características.

Esse fato remete-nos a reconhecer o caráter discriminatório do processo de recrutamento e seleção do pessoal de enfermagem. Considerando que a discriminação tem início nos critérios seletivos, acredita-se na importância desses serem estabelecidos a partir da reflexão sobre os múltiplos determinantes transituacionais; das concepções sobre o ser humano e das características e peculiaridades do trabalho e da profissão de enfermagem. A fala à seguir demostra essas considerações:

VIII “(...) Nós não temos problemas, nós admitimos enfermeiros homens, mas se a pessoa (...) for ou aparentar ser homossexual (...) Que tenha caracteristicas presentes, acentuada, nós não admitimos, porque com esse advento da AIDS a gente tinha uma resistência muito grande dos pacientes, principalmente de idade, em ser cuidado com esse tipo de pessoas. (...) não é demitido (...) mas (...) nós não admitimos." 
A situação educacional dos enfermeiros, também, é considerada um fator determinante no processo de recrutamento e seleção de pessoal. Desvelou-se nos discursos I, III, V, VIII, que os enfermeiros atribuem a responsabilidade pelo despreparo dos candidatos às Faculdades que não capacitam os enfermeiros para a realidade hospitalar. Consideram a falta de preparo dos enfermeiros tanto na área técnico-específica quanto na área da administração da assistência de enfermagem. Esse fato faz com que haja diminuição das exigências dos critérios seletivos, sendo necessário os hospitais investirem em desenvolvimento de pessoal. A fala a seguir explicita esse fato:

I "A faculdade deixa muito a desejar para elas, (...) a faculdade nunca se preocupou em dar custos do setor dela. (...) ela tem que saber o que custa o setor para o hospital, ela tem que saber quanto de encargos sociais, ela tem que saber porque gasta muito, porque não gastou, ou se gastou em excesso, o que levou a fazer isso(...) Então, eu preparei as minhas chefias aqui dentro."

Destacou-se, ainda, nos discursos VI e VIII, que a integração ensinoassistência através dos estágios extra curriculares e curriculares de escolas de enfermagem, principalmente, da disciplina de administração aplicada à enfermagem, influenciam, o processo, atraindo os enfermeiros recém-formados que estagiam nessas instituições. $O$ fato, desses enfermeiros conhecerem a filosofia e os objetivos do hospital, facilita a adaptação, desses novos enfermeiros, na instituição. Entretanto, quando a instituição não apresenta condições favoráveis de trabalho o índice de fixação, desses estagiários na instituição, depois de formados, é baixo. A fala a seguir demonstra essa percepção:

$V I$ “(...) Isso também facilita, o fato dele estagiar aqui, eles já conhecem o processo, como funciona (...) Então, é um local que para ele que é inseguro, aqui eu já conheço, é muito mais fácil dele lidar, do que em um hospital que ele não conhece absolutamente nada. Como muitos fazem administracão aqui, então se interam da rotina da enfermaria e tudo mais. Então, eles preferem começar por aqui mesmo (...)."

Outro fator desvelado, nessa temática, é a dificuldade em selecionar enfermeiros para áreas especificas, como de Obstetrícia e UTI, por requerer profissionais especializados e com experiência anterior comprovada. Isto ocorre, principalmente, devido à carência de disponibilidade de profissionais especializados no mercado de trabalho. A fala a seguir evidencia esse fato:

III "(..) enfermeira obstétrica (...) é um processo mais demorado, que a gente leva mais tempo. (...) porque a disponibilidade desse profissional no mercado é pequena, é menor em comparação às outras áreas. (...)" 
A caracterização da enfermagem é um outro aspecto determinante do processo seletivo de enfermeiros. A heterogeneidade existente na formação dos elementos da equipe de enfermagem permite que haja a promoção dos elementos de nível médio para o cargo de enfermeiro à medida em que se profissionalizam concluindo o curso de graduação.

Evidenciou-se no discurso $V$ que a legislação profissional que extingue a categoria de atendentes de enfermagem influenciou o processo seletivo de enfermeiros na medida em que proporcionou incentivo para os profissionais desenvolverem-se, sendo possivel a promoção de funcionários que concluem o curso de graduação para o cargo de enfermeiro desde que apresentem características exigidas ao cargo. Entretanto no discurso VIII revelou-se que a promoção desses funcionários que concluem o curso de Graduação em Enfermagem, é vista com restrições pela dificuldade dessas pessoas adquirirem uma postura profissional de enfermeiro. Esses aspectos podem ser resgatados nos discursos I, V, VIII. A fala a seguir representa isso:

$V$ " Eu estou bastante esperançosa com a legislação quanto aos auxiliares de enfermagem e a extinção do atendente. Isso eu acho que facilitou bastante, a nivel de rede privada, se preocupem com as diversas categorias de enfermagem (...) isso ajudou bastante a que as pessoas se preocupassem com a sua instruç̃o, com o seu preparo. Eagora nós estamos sentindo os efeitos dessa orientação.(...) Então nós temos hoje em dia assim, funcionários enfermeiros recémformados e nós estamos trabalhando a partir desse ano com as promocões dessas pessoas."

VIII "(...) pela nossa vivência aqui é uma tendência muito grande da pessoa que foi atendente por muito tempo, ou auxiliar, $\dot{e}$ muito difícil, eles mudarem a postura como enfermeiro, tem sido muito dificil."

Outro aspecto desvelado nos discursos I, VI, VIII, é que a carreira do enfermeiro está fundamentada na progressão do enfermeiro assistencial para cargos de chefia, distanciando-se assim do cuidado direto ao paciente.

A reflexão sobre a história da enfermagem e sobre os determinantes sóciopolítico-econômico poderão explicar a dicotomia existente entre o cuidado direto e a administração da assistência de enfermagem. A fala a seguir representa essa progressão na carreira do enfermeiro:

I "Envolvimento da pessoa em cargos, eu resolvi não fazer mais. (...) a pessoa é preparada por mim, para ocupar depois, seguir carreira aqui dentro. (...) Sempre enfermeiro assistencial, mesmo quando eu sei que é para algum outro cargo específico, eu recruto para enfermeiro assistencial."

As características regionais também são consideradas fatores intervenientes do fenômeno, e puderam ser evidenciadas nos discursos IV e VIII sob dois enfoques. O fato da cidade de São Paulo ser um local onde a 
tecnologia é mais desenvolvida, atrai enfermeiros de outros Estados que pretendem adquirir experiência profissional para depois retornarem aos Estados de origem para aplicarem os novos conhecimentos.

A localização do hospital, é um outro fato evidenciado, no discurso IV, que dificulta o processo de atração e seleção de pessoal, por caracterizar-se como uma barreira geográfica, dificultando a acessibilidade dos profissionais aos hospitais. Acredita-se que esse fato é predominante nos hospitais públicos por estarem em locais mais afastados do centro da cidade. Esses fatos são demonstrados nas falas a seguir:

VIII “(...) muita gente gosta de vir aqui, para São Paulo, para fazer algum curso, alguma coisa e nisso procura trabalhar para ganhar vivência (...) aqui é o lugar onde a tecnologia é desenvolvida (...) elas querem sempre vir aqui arrumar emprego para depois voltar melhor e com uma experiência adquirida para o Estado de origem."

IV "A distância, o hospital está localizado em uma região difícil, o acesso ao hospital é difícil (...) A localização não é muito convidativa, à noite não tem nada, ele está sozinho, isolado. Isso, também impede muito o funcionário de ter interesse de ficar aqui."

Foi desvelado nos discursos IV, VI, VII, que os hospitais públicos, caracterizam-se pela dificuldade de provisão de recursos humanos e materiais; pelo atraso de repasse das verbas do governo; pelos baixos salários oferecidos, pela alta rotatividade de pessoal, pelo fechamento de hospitais e de leitos hospitalares; pela falta de política de desenvolvimento de recursos humanos, pelo gerenciamento ineficiente dos serviços, e pela descontinuidade de propostas de saúde devido às mudanças de governo. Revelou-se que o processo seletivo só se tornará eficaz e eficiente quando houver uma política de saúde que dê respaldo às instituições públicas, no estabelecimento de políticas, filosofias e objetivos assistenciais aderentes às necessidades da clientela. A seguinte fala revela isso:

$I V$ '(...) primeiro a gente precisa estar (...) definindo o nosso serviço, (...) o objetivo do nosso serviço, adequar ele ao objetivo da instituiçâ, criar uma filosofia do serviço (...) qual a clientela nossa, o que ela espera da gente e o que a gente está podendo oferecer. (...) porque eu acho que quando você tem isso definido, então você consegue traçar exatamente a característica do profissional que eu quero, e ai trabalhar em um processo seletivo de uma maneira a exigir uma qualidade maior, mas eu preciso paralelo a isso um sistema de saúde mais decente, se não eu não chego a lugar nenhum (...)"

Os discursos I, II, III, V, VIII, revelaram que o quadro de pessoal no setor privado é enxuto com predominância de auxiliares e atendentes de enfermagem sendo que apenas uma minoria oferece salário compatível. Essas características influem no quantitativo e qualitativo de recursos humanos desses hospitais. As falas a seguir representam esse fato: 
II "Geralmente, os quadros dos hospitais são bem enxutos, não são aqueles quadros que você pode ficar demorando para preencher. Não pode, tem que preencher rápido.(...)"

VIII "(..) a carga horária, e o salário inicial são os maiores dificultadores. (...) O salário inicial que em relação a instituição privada, ele é baixo, está aquém das instituições privadas. Eu não posso dizer assim baixo, porque é mais que os serviços públicos, mas está aquém da média das instituições privadas, aqui da redondeza. (...)"

A situação econômica do país é um outro fator determinante do processo que pode ser evidenciado nos discursos II, III, VI. Segundo a percepção dos elementos que vivenciam o processo seletivo, os enfermeiros buscam, principalmente, melhores condições salariais para suprir suas necessidades de sustento em detrimento das necessidades sociais de melhores locais e equipe de trabalho. Os benefícios oferecidos, como assistência médica, cesta básica e bolsa de estudo, também são atrativos por representar um salário indireto. As falas a seguir demonstram isso:

II "Os benefícios, também facilitam muito, porque salário, não é só o salário nú e crú que interessa. Nessa pesquisa que eu fizo ano retrasado sobre rotatividade, eu descobri que muitos funcionários ficam aqui por causa da bolsa. (...) a gente ganha um plano gratuito de saúde, e a gente sabe muito bem quanto custa um plano de saúde (...) para muita gente (...) jamais poderia ter atendimento em um hospital particular Então os beneficios atraem muito."

Os discursos II e V evidenciaram que em decorrência da situação econômica do pais, os enfermeiros necessitam, atualmente, trabalhar em dois empregos, mesmo sendo cansativo e desgastante. Essa realidade gera a necessidade dos hospitais modificarem seus horários de trabalho e seus critérios seletivos na tentativa de compatibilizar as necessidades dos enfermeiros e da organização. Os trechos dos discursos, a seguir, representam esse fato:

II "(...) porque assim é uma realidade, quer a gente queira ou não, as pessoas trabalham com dois empregos, eu sei que não é bom, mas é a realidade. Então, a gente estava tendo dificuldade de contratar, porque os horários não batiam. A pessoa ia super bem no processo, e não batiam os horários. Então, a gente fez uma reunião, todas nós resolvemos mudar em meia hora o horário de alguns setores(...)."

$V$ 'Em princípio, acho assim, que dois empregos tornou-se uma realidade (...) Alguns anos atrás, talvez nós não selecionaríamos essa candidata, porém isso tornou-se uma realidade, dificilmente hoje en dia, você tem um só emprego, até porque são seis horas, as pessoas acham que dá para manter dois vínculos. (...)." 
A dinâmica organizacional caracterizada pelos aspectos estruturais, pelas relações de poder, pela política de recursos humanos, pelos pressupostos, objetivos e filosofia institucionais determinam a operacionalização do processo. A fala a seguir representa isso:

$V$ "Cada instituição é diferente, porém eu acho assim que existe umas que são assim: órgãos públicos você sabe que existe também um certo padrão, tem uma certa filosofia, tem fins lucrativos. A nossa instituição é um pouco diferente, porque nós temos ainda aqui dentro da sua filosofia por pertencer à uma Congregação, uma filosofia bastante forte de prestação de serviços que diz respeito muito à pessoa humana, sua filosofia de vida, não que isso discrimine as outras candidatas, mas uma certa maturidade, uma certa experiência."

Depreendeu-se disto, que há interdependência entre o planejamento da assistência de enfermagem, a estrutura do Serviço de Enfermagem e a filosofia do hospital no processo de recrutamento e seleção de pessoal. Os pressupostos organizacionais e a forma como o hospital estrutura seus programas influenciam o processo facilitando ou não a atração e a seleção de enfermeiros. As falas a seguir demonstram esses determinantes:

IV “(...) a própria dificuldade nossa do Serviço, como a gente não tem o serviço estruturado, tudo isso é um impedimento. Você também desmotiva às vezes o candidato, porque você não tem muito a oferecer (...) é um impedimento, porque as vezes as pessoas buscam a capacitação, o aperfeicoamento, profissionalmente um crescimento e nem sempre você está podendo oferecer isso, e há pessoas que se interessam muito nessa linha, mas é intenção da gente é mudar isso. Porque também não é só salário que desmotiva, mas as vezes algumas outras coisas também são fatores de peso nisso."

VIII "(...) as pessoas acham que aqui a exigência é muito grande e que assumem a unidade com um número muito grande de pacientes que nós somos muito exigentes, que aqui parece regime militar esse é um fator colocado por elas como dificultador."

Evidenciou-se ainda, nos discursos IV e VII, que nos hospitais públicos a estrutura decisória do processo seletivo é centralizado nas Secretarias de Saúde e sofre influência direta do poder político partidário. Percebe-se que quando há uma mudança partidária nas Secretarias, as políticas de recursos humanos também são modificadas. Assim, a operacionalização do processo dá-se de forma distante, em outros estratos da estrutura organizacional, não permitindo uma real articulação entre as necessidades da organização e as do indivíduo. A fala a seguir revela essa realidade:

VII "(...) Os concursados são mais a nivel de Secretaria. A nomeação, a escolha de vaga pode ser até descentralizado, que geralmente é, mas é coordenado a nível de Secretaria. (...) A gente 
só caracteriza a vaga, então a Secretaria vai nomear um número $X$ de pessoas, eles entram em contato com a regional, então a regional vai distribuir as vagas pela região. (...) o nosso papel nesse momento é caracterizar as vagas (...) com a chefia de enfermagem (...) de tantas enfermeiras (...) para o horário da manhã (...) para a tarde e (...) para noite (...) E eu vou passar isso para região e vai chegar na Secretaria. (...) ele (...) escolhe uma vaga (...) A coisa é muito bem estruturada, até para não haver ninguém recorrendo, abrindo um processo contra (...) Quando há excedentes de concurso, que não foram chamados, eles serão chamados antes (...) de estourar uma contratação. (...) quando esgotou todos os aprovados em concurso remanescente (...) vamos partir para contratação ou então publicar um novo concurso público."

No discurso VII foi possível desvelar que o estatuto dos hospitais públicos prejudica a seleção e a retenção de profissionais qualificados e comprometidos com o trabalho, por não contemplar medidas que possibilitem o gerenciamento da equipe de enfermagem de maneira justa, diferenciando os bons e maus funcionários.

Resgatou-se que nos hospitais públicos a responsabilidade do indivíduo está comprometida, pelo fato dos direitos dos funcionários estarem assegurados e as suas obrigações e deveres não serem privilegiados. Assim, a falta da coresponsabilidade necessária entre a instituição e o indivíduo gera resultados insatisfatórios. Essa realidade pode ser demonstrada na fala a seguir:

VII "(...) a estabilidade na prefeitura, então aquele que está efetivo que tem muito tempo de casa (...) ele não corre o risco de ser dispensado. (...) a prefeitura é diferente porque no particular, quando aumenta muito o salário, eles dispensam e na prefeitura a gente não percebe isso. Mas para você ter um bom recrutamento eu não colocaria isso. Você tem muita dificuldade aqui na prefeitura, a dificuldade de pessoal que reduz, de repente tem algumas pessoas que ficam acomodadas, que você tem dificuldade de trabalhar, então a própria estabilidade, também, tem esse negativo. (...) o Estatuto favorece muitas regalias. (...) jornada de trabalho a nível de carga horária, a jornada de seis horas, as licenças médicas que ele acaba conseguindo sem muita dificuldade, então ele se afasta muito por licenças médicas. (...) o salário diminui, então ele começa a faltar, quando o salário melhora ele retorna numa boa. (...) o funcionário não valoriza essa parte. (...) Então ele só se prende por aquele salário, que não está como ele gostaria, mas o resto todo ele não vê. (...) Nós temos esse tipo de funcionário, mas em contra partida você tem o outro que não tem compromisso (...) nos novos, eles não tem compromisso, não assumem o compromisso como os mais antigos. Então o Estatuto, eu acho que prejudica muito você ter uma qualidade boa de profissionais, porque você não tem como trabalhar." 
Os enfermeiros são unânimes em considerar que a política de recursos humanos, com planos de carreira, treinamento, aperfeiçoamento, desenvolvimento de pessoal, plano de saliários e benefícios e jornada de trabalho compatíveis, facilita e favorece a atração e a retenção dos enfermeiros na organização, trazendo vantagens para a instituição e para o indivíduo. No discurso II evidenciou-se que quando as instituições têm uma política de recursos humanos de valorização do cliente interno, conseguem recrutar e selecionar facilmente e manter o pessoal qualificado, motivado e produtivo. $O$ funcionário quando satisfeito é um ótimo elemento para recrutar novos funcionários, daí a necessidade da administração considerar as condições de trabalho que proporcionam satisfação ao funcionário. A fala a seguir demonstra isso:

II "(...) eu consegui ver que a principal fonte de recrutamento foi de funcionários (...) eu constatei que está documentado, que é importante o recrutamento de colegas, de ex-funcionários, na medida que a gente constata, então é uma ênfase que a gente acaba dando até um "feed-back", para a administração (...) Como é importante tratar bem os funcionários em termos de beneficios, de pagar direitinho, de tratar bem o funcionário, de ouvi-lo. Porque se ele sai daqui com o pensamento negativo da empresa, ele vai fazer propaganda negativa da empresa. (...)"

Foi exposto nos discursos que o fato da instituição não possuir uma política de pessoal de valorização de recursos humanos, com diretrizes pro-ativas que contemplem as necessidades individuais, organizacionais e da sociedade provoca, nos enfermeiros, desmotivação e desinteresse pelo trabalho do hospital, ocasionando baixa procura e alta rotatividade de enfermeiros. Com isso reduzemse os critérios seletivos, possibilitando a admissão de enfermeiros recém-formados e até desqualificados. Outra conseqüência é que os candidatos adquirem experiência e depois procuram outros hospitais com melhores condições de trabalho e, principalmente, de salário.

Esse fato compromete o processo de recrutamento e seleção de enfermeiros, pois não permite que sejam estabelecidos critérios rigorosos, devido à preocupação excessiva com o quantitativo e não com os aspectos qualitativos de pessoal.

Por outro lado, segundo o discurso I, o fato de admitir recém-formados é um aspecto positivo por ser, esse elemento, considerado alguem mais facilmente modelável. As falas a seguir demonstram essas considerações:

I "(..) eu acho que todas as características de personalidade, (...) você consegue contornar e desenvolver nela, porque eu tenho um perfil muito jovem, esse é o primeiro emprego delas. (...) a visão que elas têm de fora é muito pequena e essas pessoas, a maioria delas acabam se fixando comigo."

$V I$ " (...) Porque eu não tenho condiç̃es de exigir muito, por causa da procura que eu tenho que é pouca e a rotatividade que é muito grande dos enfermeiros. O enfermeiro acaba pegando 
experiência aqui e vai embora. Não adianta eu ser extremamente exigente, porque aí eu não aprovo mais ninguém."

Foi desvelado nos discursos II e VIII que a administração dos hospitais não está preocupada em estabelecer uma política efetiva de valorização de recursos humanos internos, acreditando que o pessoal pode ser substituído facilmente. As instituições hospitalares não percebem a importância da valorização dos recursos humanos, na melhoria da qualidade de assistência. As enfermeiras consideram que os hospitais, teoricamente, investem em recursos humanos, mas na prática o que é valorizado é a tecnologia. Esse fato pode ser evidenciado nas falas a seguir:

II "Mas a empresa, a administração está preocupada em segurar esse profissional? É um erro, as pessoas acharem que: Não faz mal esse aqui sair, eu arrumo um outro, tão bom quanto! Muito pelo contrário, quantas vezes a gente perde bons funcionários, e a gente não consegue repor, com alguém da qualidade daquele. Só os custos, também, gastos com admissão, demissão registrar em carteira."

VIII "(..) Mas o que eu acho de mais grave na educação continuada, que eu sinto em todo serviço que as pessoas falam na prática não ocorre o que existe na teoria. O que existe na teoria é que a Instituição, as chefias (...) valoriza (...) mas isso fica no discurso, porque na verdade, na hora para tirar alguém, para substituir férias, folgas é sempre o pessoal da Educação Continuada (...) não existe um valor em relação a isso. (...) as pessoas ainda não estão totalmente acordadas, pelo menos aqui na instituição, que você investir em recursos humanos você melhora a qualidade que a qualidade você não melhora só com tecnologias modernas, de ponta (...) Porque se as pessoas não souberem manipular a tecnologia, aquilo não vai funcionar, ao contrário, só vai dar prejuizo porque vai quebrar tudo. (...) falta isso, mais valorização em relação a isso. (...) eu acho também que as enfermeiras que trabalham na educação aqui fazem um esforço muito grande em relação as pessoas, para se valorizarem é... perante todo o pessoal porque na verdade a gente trabalha em grupo, o grupo da educação, mas um pouco em dissonância com a filosofia. Quer dizer a nossa filosofia é uma, por isso que as vezes até revolta, e a filosofia Instituicional é outra vê mais o enfoque na tecnologia do que nos recursos humanos, eu fico triste com isso, mas infelizmente, quer dizer, na verdade não pode mudar. E quando a gente vai conhecer outros lugares, vai estudando, vai lendo mais e vai vendo que isso é importante, cada vez mais você vai ficando mais decepcionada."

Ficou evidente que o processo seletivo só é deflagrado quando há necessidade de pessoal de enfermagem devido à ampliação do número de leitos 
hospitalares ou pela movimentação natural do pessoal nas organizações por demissões, promoções, transferências e dispensas. O dimensionamento do quadro de pessoal de enfermagem depende da administração do hospital sendo que os enfermeiros não têm poder decisório sobre a criação de cargos. As seguintes falas representam isso:

I "(...) porque vai depender das vagas, de abrir setores, da dinâmica propriamente, do serviço (...) as que já estão aqui dentro em termos de promoção, ai a criação de cargos não tem o menor problema. Os externos, eu preciso ter a vaga em condicões de ser ocupada. (...) criar cargos para gente externa, aí depende de um planejamento administrativo, aí já não depende de mim."

III "(...) um passo obrigatório dentro da instituição para todos os cargos universitários, embora não seja decisivo no processo de seleção, onde a Superintendência entrevista este candidato. A intenção da Superintendência é tá se envolvendo no processo de seleção (...) não tem qualquer poder de decisão na minha seleção. $E$ filosofia da instituição de estar desde o processo seletivo estar se aproximando do candidato, do profissional que em potencial poderá estar trabalhando aqui com a gente."

Um outro aspecto refere-se à avaliação do processo seletivo. Nos discursos I, III, VI e VIII ficou evidente que não há avaliação formal do processo de recrutamento e seleção de enfermeiros. Ocorre uma avaliação informal dos resultados baseada na rotatividade e no acompanhamento dos funcionários recém-admitidos. Apenas o discurso II evidenciou a importância da realização formal do processo seletivo para a sensibilização da administração do hospital, quanto à importância da valorização dos recursos humanos. Entretanto, esta enfermeira julga ser difícil estabelecer um processo de avaliação contínuo, devido às mudanças na política de recursos humanos e à falta de condições propícias.

O discurso VI, mostrou que a avaliação informal do processo realizada pelos enfermeiros das unidades não está fundamentada na realidade do mercado de trabalho, ocorrendo divergências entre o enfermeiro selecionador e o das unidades a respeito dos candidatos aprovados.

I "(...) periodicamente, em relação aos enfermeiros, eu não faço avaliação do processo. (...) eu não tenho rotatividade, então eu suponho que o meu processo está dando certo. (...) se eu tivesse muita rotatividade, eu teria que fazer uma análise dos diferentes passos que eu dou nesse processo, porque eu acharia que alguma coisa estaria dando errado. Então, como eu não tenho essa rotatividade de enfermeiros, eu não faço essas mudanças, eu tenho mantido o mesmo processo sem ter muitos problemas."

$V I$ “(...) a maior dificuldade que eu tinha, é que apesar de já ser um costume receber o recém-formado, existia muita impaciência com esse recém-formado. Porque você tem que dar um tempo, não é 
em trinta dias que ele vai se soltar, comecar a ter iniciativa, resolver as coisas, e as pessoas queriam isso já, desse enfermeiro."

Depreendeu-se, dos discursos I, II, III, V e VIII, que o processo seletivo é caracterizado pela subjetividade, devido à própria natureza da interrelação humana. Os julgamentos sobre os candidatos feitos durante o processo seletivo não permitem, muitas vezes, uma decisão correta. O processo compartilhado com os enfermeiros dos Setores e com os psicólogos tende a diminuir essa subjetividade, porém é pouco adotado devido às condições organizacionais e até mesmo ao despreparo dos profissionais. Devido a esses limites do processo, o tempo de três meses de experiência é valorizado, sendo que nesse período o candidato pode ser efetivado ou não. As falas à seguir representam essa subjetividade:

I "Eu acho que a entrevista com a psicóloga me dá muitos subsídios para eu trabalhar (...) já me dando o perfil do candidato, eu tenho condiçoes de direcionar a minha entrevista para o que eu quero. Eu acho que isso é importante, não é feito por mim, mas me facilita."

II "É uma coisa muito subjetiva, e eu, inclusive sempre critiquei isso, porque é uma coisa boa e uma coisa ruim, a gente tem que ter muito "feeling", eu não sei se isto está errado ou certo, mas está muito na mão de quem está entrevistando, ter o "feeling" de sacar." (...) você tem que sentir lá na hora, e é você que está ali e tem que sentir se a pessoa tem probabilidade de dar certo ou errado. (...) ninguém é adivinho, as vezes, uma pessoa que foi muito bem no processo seletivo, pode dar errado, assim como, aquela que não foi muito bem, é um ótimo funcionário. Então assim, a gente tem que entender que é passivel de erro, mas a gente tem que tentar acertar no global. (...) por isso que a gente dá valor para os três meses. Porque tudo o que a gente errou e não detectou na entrevista, a gente tem três meses para efetivar ou não o candidato."

Evidenciou-se, como ponto comum, dos discursos que os enfermeiros que assumem o processo de recrutamento e seleção de pessoal de enfermagem referendam a cultura organizacional pela introjeção dos valores, crenças e pressupostos organizacionais.

Ainda, o enfermeiro que desenvolve o processo seletivo é aceito pela estrutura de poder da organização, que delega, para esse elemento, o poder para selecionar indivíduos que apresentem valores e crenças semelhantes aos da organização.

Desvelou-se que os enfermeiros não têm consciência sobre o papel que desempenham como responsáveis pelo processo de recrutamento e seleção de enfermeiros, uma vez que, em nenhum momento, questionam o fato de terem sido indicadas para realizarem essa atividade. 
Nos discursos ficou evidente que os atributos psicologicos e atitudinais dos candidatos são predominantes em relação ao conhecimento específico de enfermagem por serem prioritários na admissão de enfermeiros para que se adequem às características e pressupostos organizacionais. Assim, busca-se no processo admissional avaliar, principalmente, as características pessoais, as crenças, os valores e a capacidade de cumprir as responsabilidades do cargo de acordo com as diretrizes e padrões de desempenho previstos pela organização.

Resgatou-se, também, que na definição dos atributos desejáveis aos enfermeiros estão embutidos valores pessoais, do elemento que seleciona, bem como, os significados que esses enfermeiros têm a respeito do Ser enfermeiro e da enfermagem. Assim são valorizados atributos altruísticos, caritativos e disciplinares como de resignação, de conformismo, de hierarquia, de obediência, de passividade, de prudência e de auto-controle.

Outro aspecto desvelado na percepção, dos enfermeiros que vivenciam o processo de recrutamento e seleção é que está ocorrendo uma mudança no perfil dos enfermeiros sendo considerada, uma perda, o fato da enfermagem tornar-se uma opção e não uma vocação. Assim, os enfermeiros não se sujeitam mais a esquemas de trabalhos rígidos, baixos salários e horários extenuantes. Resgatase que há choque de valores entre os pressupostos organizacionais e as necessidades pessoais dos enfermeiros.

Pode-se pensar que atualmente as gerações estão em busca de uma melhor qualidade de vida determinando suas formas de trabalho, de acordo com as suas opções de vida e não mais estabelecendo uma relação inversa. Isso pode ser revelado nas falas a seguir:

$V$ "Infelizmente, eu tenho impressão de que a enfermagem está se tornando uma opção e não vocação. Você percebe a diferença com os profissionais mesmo."

VIII "A queixa (...) são às oito horas. (...) são quarenta horas com duas folgas referentes aos sábados, domingos e feriados (...) só que as pessoas de uns tempos para cá só querem trabalhar em instituiçoes que trabalham seis horas. Embora a maioria das instituições, mesmo particulares, quando a enfermeira entra na assistência direta, ela entra com seis horas, depois que assume (...) uma chefia de unidade, encarregada de alguma coisa, ela passa a fazer oito horas. (...) instituições (...) privada, são assim (...) as instituiç̃es públicas não, são seis horas (...) mas o salário (...) está (...) a desejar. (...) aqui é um hospital que tem uma característica de rotativo, (...) mais, principalmente o enfermeiro, por isso que eu falei para voce, as pessoas entram aqui para ganhar uma determinada experiência (...) depois vão embora."

Um último aspecto desvelado, é a importância da conscientização dos enfermeiros sobre os reais interesses, valores, crenças, políticas e pressupostos 
organizacionais, expresso somente no discurso VIII. Evidencia-se que o processo de conscientização dos enfermeiros é muito sofrido, causando muita revolta e decepção.

Depreendeu-se que a conscientização dos enfermeiros, a respeito dos determinantes intra e extra-organizacionais que interferem no processo seletivo, é importante para que haja mudanças nas políticas administrativas e na cultura organizacional. Dessa forma o processo será baseado em critérios relacionados única e exclusivamente com o trabalho, não tendo conotação discriminatória. A fala seguinte revela isso:

VII “(...) na verdade a gente trabalha em grupo, o grupo da educação, mas um pouco em dissonância com a filosofia. Quer dizer a nossa filosofia é uma, por isso que as vezes até revolta, e a filosofia Instituicional é outra (...) vê mais o enfoque na tecnologia do que nos recursos humanos, eu fico triste com isso, mas infelizmente, quer dizer, na verdade não pode mudar. (...) E quando a gente vai estudando, vai lendo mais e vai vendo que isso é importante, cada vez mais você vai ficando mais decepcionada (...) eu procuro fazêlas enxergar, abrir o olho para isso, mas por outro lado eu vejo que as vezes eu vou abrir o olho eu deixo elas assim revoltadas, aí eu me retráio um pouco, por que eu também não posso prejudicar."

O cenário do recrutamento e seleção de enfermeiros desvelado pelos sujeitos que vivenciam o processo na prática da enfermagem possibilitou evidenciar múltiplos determinantes que envolvem a ação humana no trabalho da enfermagem, abrindo um novo leque de inquietações e indagações sobre o fenômeno.

Desvelou-se que o processo seletivo é um fenômeno dinâmico de compatibilização das necessidades organizacionais è individuais, influenciado por múltiplos determinantes transituacionais decorrentes do contexto ambiental e organizacional. Como tal, não pode ser visualizado com a simplicidade, de apenas, preencher os cargos de enfermeiros existentes nas instituições hospitalares voltado, exclusivamente, para a aplicação de procedimentos burocráticos e discriminatórios decorrentes do vínculo empregatício.

Para tanto, evidencia-se a necessidade do ensino e da prática do processo seletivo estar fundamentado na constante reflexão sobre o vivido e o vivencial da enfermagem, possibilitando o exercício de uma prática transformadora e aderente às necessidades da sociedade.

Dessa forma, acredito ter nessa pesquisa evidenciado uma das facetas da gestão de recursos humanos, sob a optica dos enfermeiros responsáveis pelo processo seletivo, abrindo um novo leque de inquietações no que tange o pensar sobre recrutamento e seleção em enfermagem. 


\section{REFERÊNCIAS BIBLIOGRÁFICAS}

1. ALMEIDA, M.C. P. de; ROCHA, J.S.Y. O saber de enfermagem e sua dimensáo prática. 2.ed. São Paulo, Cortez, 1989.

2. AQUINO, C.P. de Administracão de recursos humanos: uma introdução. São Paulo, Atlas, 1980.

3. CHIAVENATO, I. Administração de recursos humanos, 2.ed. São Paulo, Atlas, 1981. v.2

4. CHIAVENATO, I. Introduçăo à teoria geral da administracăo. 3.ed. Săo Paulo, McGrawHill, 1983.

5. CORADI, C. D. O comportamento humano em administracăo de empresas. Sáo Paulo, Pioneira, 1985.

6. GOMES, E.L.R. Administração em enfermagem: constituição histórico-social do conhecimento. Ribeirăo Preto, 1990. 188p. Tese (Doutorado) - Escola de Enfermagem de Ribeirão Preto, Universidade de São Paulo.

7. GONÇALVES, E.L. Administracão de recursos humanos nas instituiçoes de saúde. São Paulo, Pioneira, 1987.

8. JUCIUS, M. Administração de pessoal. São Paulo, Saraiva, 1977.

9. LEITE, M.M.J. O ensino da disciplina administracão aplicada à enfermagem: compreensão das graduandas. São Paulo, 1994p. Tese (Doutorado) - Faculdade de Educação, Universidade de São Paulo.

10. LOBOS, A.J. Administracão de recursos humanos. São Paulo, Atlas, 1985.

11. LUCENA, M.D. da S. Planejamento de recursos humanos. São Paulo, Atlas, 1991.

12. MARTINS, J. Um enfoque fenomenológico do currículo: educação como poíesis. São Paulo, Cortez, 1992.

13. MARTINS, J. ; BICUDO, M.A.V. A pesquisa qualitativa em psicologia: fundamentos e recursos básicos. São Paulo, Moraes, 1989.

14. PEREIRA, L.L. ; LEITE M.M.J. Recrutamento e seleção do pessoal de enfermagem. In: KURCGANT, P. (coord) Administracăo em enfermagem. Săo Paulo, EPU, cap8, p. 97. $105,1991$.

15. PONTES, B.R. Planejamento, recrutamento e selecão de pessoal. São Paulo, LTR, 1988.

16. SILVA, M.J.P. et al. Educacăo continuada: estratégia para o desenvolvimento do pessoal de enfermagem. São Paulo, Marques-Saraiva, 1989.

17. STUER, R.S.; SILVA, M.J.P. da O processo de introdução de recursos humanos em organizaçoes públicas de saúde. Acta Paul. Enf., v.3 n. 3, p. 85-91, 1990. 
18. TAYLOR, F.W. Princípios de administracão científica. 7. ed. São Paulo, Atlas, 1970.

19. TOLEDO, F. de Administração de pessogl: desenvolvimento de recursos humanos. São Paulo, Atlas, 1987.

20. WERTHER, W.B. ; DAVIS, K. Administração de pessoal e recursos humanos. São Paulo, MeGrawhill, 1983.

PERES, H. H. C.; KURCGANT, P. The phenomenon of recruitment and selecting nurses in the hospital: a phenomenon approach. Rev.Esc.Enf.USP, v.31, n.1, p. 129-49, apr. 1997.

This study had the purpose of showing the recruitment and selective process of nurses from their own experiences going through this process. The phenomenology was used as the methodological course, the phenomenon was based on the references by Joel Martins. The study was done from the speeches of eight nurses who went through the recruitment and selective process. The analysis of the speeches followed the moments of the phenomenological description, reduction and understanding until revealing the essence of the recruitment and selective process of nurses. From the phenomenological analysis of the speeches it was possible to get the aspects that represent the general understanding of the recruitment and selective process of nurses. In this way, the essence of the phenomenon was characterized by the relation among the man, the Company and the society, these relations were influenced by several determinants beyond the situation. Through this perspective, new horizons were opened concerning the thoughts about the recruitment and selective process of the nursing staff.

UNITERMS: Recruitment and selecting nurses. Human resource management, human resource nurses.Human recruitment and retention. 